possible at greater range. In my own practice lightweight sets will function in buildings for up to 3 miles $(4.8 \mathrm{~km}$.) and in the open air for up to 5 miles $(8 \mathrm{~km}$.).

Servicing.-An adequate service network is essential, particularly in the early months. Most doctors have had no real difficulties, but those in isolated areas may find servicing a problem. Manufacturers quote a fault rate of one a year for a modern transistorized set, but the older valve equipment was less reliable. Progress in design continues to be made.

\section{Planning and Installation of Systems}

There is no substitute for adequate initial planning, and a useful guide is published by the Institute of Office Management. A doctor or a partnership should consider the ways in which radio could be integrated into the pattern of the practice, and only then should an approach be made to manufacturers. Technical representatives may be able to demonstrate the range obtainable, may suggest helpful modifications, and will be able to supply detailed information and estimates of the cost, but the basic organization of the system must be determined by the features of the practice.

When details have been agreed an application is submitted to the Radio Services Department of the Post Office for a channel allocation. It is usual to do this through the manufacturer, as details of the equipment to be installed will be required. When the frequency has been allocated the equipment may be ordered and installed, the entire procedure probably taking about three months.

\section{Summary}

The majority of radiotelephone systems in use by general practitioners give helpful and reliable service. Most doctors would wish for cheaper equipment, but few have regretted their purchase. Problems occasionally arise, but are seldom insuperable if the advance planning has been adequate. Progress in the design of lightweight equipment may make the lightweight set the equipment of choice in future.

I would like to thank the Practice Organization Committee of the College of General Practitioners, and all those doctors who supplied me with detailed information about their systems. Dr. J. E. Struthers, of the Ministry of Health, and Mr. D. R. Golding, Statistical Officer of the Oxford Regional Hospital Board, gave me valuable advice. Technical assistance and information of great help was provided by Pye Telecommunications Ltd., Motorola, Cossor, Storno-Southern, and Ultra.

\section{REFERENCES}

Hart, R. D. C., Hargrave, M. J., and Mitchell, P. S. (1961). F. Coll. gen. Practit., 4, 446

Hodgkin, K. (1954). Lancet, 2, 1323.

Private Mobile Radio Telephone Systems. Published by the Institute of Office Management, 167 Victoria Street, London S.W.1. Price 3s. 6d.

\section{NEW APPLIANCES}

\section{Transvaginal Pudendal Block}

Dr. J. H. N. FerRIS, senior tutor, Jubilee Obstetric Unit, Belfast City Hospital, writes: In recent years there has been considerable controversy over the best methods of anaesthesia for low-forceps deliveries by general practitioners. The main criticism of pudendal block appeared to be the difficulty in unpractised hands in directing the needle accurately to the ischial spines. By using the transvaginal route this difficulty can be overcome. Provided the ischial spines can be palpated an accurate pudendal block can be easily achieved with the minimum of handling and a reduction in the amount of local anaesthetic.

The great interest shown by general practitioners on refresher courses in the method, and the inquiries concerning the availability of the guide (Fig. 1), prompted this description of the technique of its use.

The pudendal-nerve-block guide is clipped on the lateral aspect of the left index finger and steadied with the thumb (Fig. 2). The tip of the finger is inserted in the vagina and is first placed on the left ischial spine. The distal end of the guide will then lie inferolateral to the spine. Injection at this point will block the nerve as it rounds the spine. After withdrawal of the needle by pronating the hand and forearm, the finger can now be placed on the right ischial spine, the guide again pointing accurately to the inferolateral aspect of the spine. Five millilitres of $0.5 \%$ Xylocaine (lignocaine) is injected at each spine and $10 \mathrm{ml}$. in the labial and perineal region.

The rounded tip of the guide prevents catching and tearing of the vaginal mucosa. The split ring allows for adjustment to fit any size of finger. The needle (Luer fitting) is $\frac{1}{2}$ in. $(1.3 \mathrm{~cm}$.) longer than the guide, thus making it impossible to advance it too far.

The needle and guide are available from Chas. F. Thackray Ltd., Leeds, price $£ 22 \mathrm{~s}$.

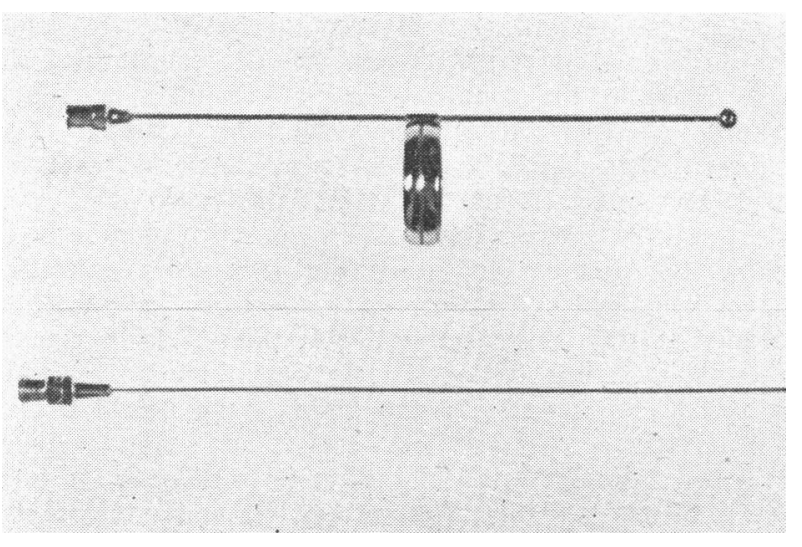

FIG. 1.

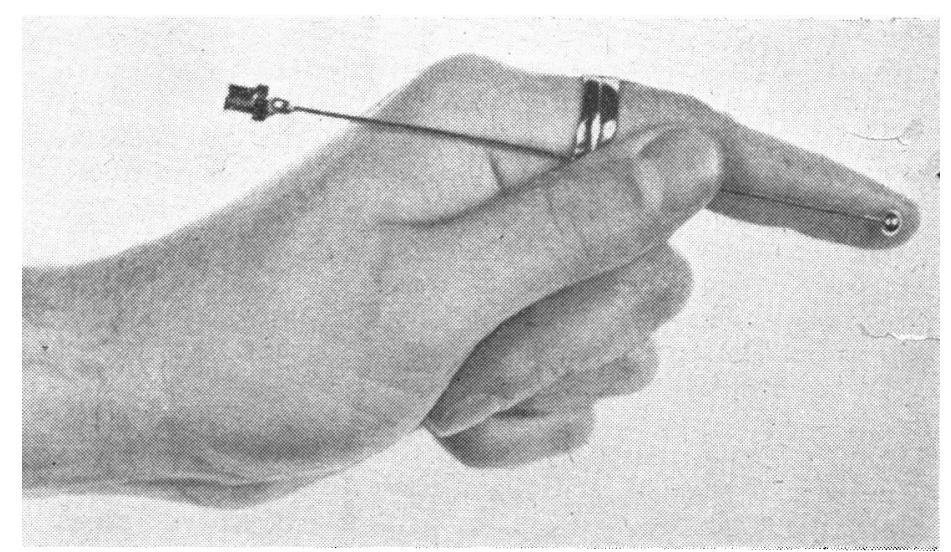

FIG. 2. 